\title{
Design de Superfície e Trabalho de Mulheres: Levantamento de Literatura
}

\author{
Surface Design and Women's Work: Literature Survey
}

BONIFÁCIO, Bruna Carmona; Mestranda; Universidade Federal do Paraná

bruna.c.bonifacio@gmail.com

CORRÊA, Ronaldo de Oliveira; Doutor; Universidade Federal do Paraná

rcorrea@ufpr.br

\section{Resumo}

Este artigo tem por objetivo apresentar um levantamento de literatura da produção acadêmica que tem o design de superfície e o trabalho de mulheres como objeto de estudo. Para tanto, foi mapeada através de revisões bibliográficas assistemática e sistemática, literatura que relacionasse os temas. Estas são apresentadas e analisadas de forma comparativa. Como resultado, o artigo aponta um panorama da arte e de lacunas sobre o assunto em pesquisas nacionais.

Palavras Chave: design de superfície; trabalho de mulheres; gênero.

\section{Abstract}

This article aims to present a literature survey of the academic production that has the surface design and the work of women as study object. For that, it was mapped through systematic and systematic literature reviews, literature that related the themes. These are presented and analyzed in a comparative way. As a result, the article points out an overview of the art and gaps on the subject in national surveys.

Keywords: surface design; work of women; gender.

\section{Introdução}

O design neste trabalho é entendido em diálogo com Forty (2007) e Cardoso (2008), que o consideram uma atividade de criação, projeto e produção. Cardoso $(2008$, p.196) questiona a forma como se define quem é ou não considerado(a) designer, apresentando exemplos de trabalhos de design importantes realizados por "indivíduos extraordinários" anterior ao período de organização formal da profissão, e defende que as contribuições de vários profissionais não devem ser ignoradas por esse motivo. O autor complementa afirmando que hoje existe um "número significativo de profissionais ativos" que "permanece fora dos trâmites do ensino superior, e nem por isso são menos designers". Concordamos com Pereira $(2014, p .11)$ que design está mais relacionado ao processo de fazer e produzir objetos, e que essa prática pode ser considerada como uma atividade realizada por sujeitos de áreas diversas, e não somente o trabalho do(a) profissional com formação específica.

O objetivo deste texto é apresentar um levantamento de literatura da produção acadêmica 
que tem o design de superfície e o trabalho de mulheres como objeto de estudo, pois consideramos que as práticas e as pessoas pertinentes a esse universo se encontram no registro de criadores(as) ativos(as) fora dos cânones do design. Mesmo que muito presentes nas criações, projetos e produções brasileiras, como veremos no decorrer do texto, atividades relacionadas geralmente não são conhecidas ou reconhecidas. Logo, documentar, descrever e analisar a trajetória de aprendizado e trabalho de mulheres no design pode auxiliar em diferentes perspectivas tanto sobre a participação das mulheres na história do design, quanto sobre a história do design.

Por design de superfície, entendemos assim como Rüthschilling (2008), uma área do design na qual a superfície - seja ela papel, têxtil, cerâmica, sintética ou outra - é amplamente explorada através de diferentes técnicas, como estamparia, tecelagem, jacquard, malharia, tapeçaria, revestimentos para paredes e pisos, confecção de projetos para papelaria, entre outras. No âmbito da prática caracteriza-se por sua interdisciplinaridade e relação próxima a outras áreas da arte, do artesanato e do design, como o design de moda, design gráfico, design de produto e design de interiores. $\mathrm{O}(\mathrm{a})$ criador(a) de design de superfície projeta e cria texturas "visuais e táteis que serão usadas para constituir ou atribuir qualidade para as superfícies", ele(a) o faz considerando função e estética adequadas ao "contexto sociocultural e as condições de produção" (RÜTHSCHILLING, 2008, P. 55).

Às práticas do design de superfície, cabem boa parte das atividades historicamente acessadas pelas mulheres, em especial, na disciplina do design. Esta pesquisa tem como parte de suas justificativas as considerações de Rubino (2010, p.331), quando ao investigar pontos de encontro das trajetórias profissionais da arquiteta Lina Bo Bardi e da designer Charlotte Perriand, sobre uma "silenciosa divisão de trabalho por gênero" nessas práticas profissionais. A autora analisa casos de trajetórias "bem-sucedidas, com carreira, obra e visibilidade", com o intuito de argumentar que essa divisão de trabalho acontece não somente com profissionais que estavam "à margem", como também com as mulheres que "frequentaram o centro" dos campos nos quais atuavam.

Em seu artigo, Rubino (2010) sugere que as relações entre design e gênero estão envolvidas em relações hierárquicas de poder, nas quais as desigualdades entre homens e mulheres são naturalizadas, agindo também nos artefatos e nas práticas de trabalho.

Com o intuito de investigar o tema desse estudo, na primeira etapa fizemos buscas em livros, teses, dissertações e artigos tanto de conceitos e principais autores, quanto de lacunas presentes nas pesquisas já realizadas. Para traçar esse panorama da literatura das produções científicas que abordam as construções de gênero e as suas possíveis influências no design de superfície, realizamos pesquisas bibliográficas sistemáticas e assistemáticas.

Na etapa sistemática utilizamos o método de Conforto, Amaral e da Silva (2011), realizamos as buscas nas bases Capes, Scopus e BDTD (Biblioteca Digital de Teses e Dissertações), utilizando e cruzando 22 termos na língua portuguesa e inglesa, a saber: design de superfície/surface design, design têxil/textile design, design de moda/fasion design, design de estampas/pattern design, design, gênero/gender, relações de gênero/gender relations, mulher/woman, feminista/feminist,female, trabalho da mulher/woman's work, mulheres designers/women designers.

Depois de executadas todas as etapas previstas no método de Conforto, Amaral e da Silva (2011), percebemos como resultado que considerável parte da amostra possuía títulos e palavraschave em um contexto que envolve o design de superfície, porém, seus resumos se mostraram mais 
específicos de outra área do design, como design de interiores, de móveis e gráfico. Notamos também que as expressões que poderiam ser pensadas como menos específicas da área do design de superfície - como design e "gender", e "women designers"- foram as que mais apresentaram resultados relacionados ao tema.

Os resultados não foram considerados satisfatórios pois não encontramos pesquisa que abordasse o design de superfície no Brasil e questões de gênero, então, para aprofundar a pesquisa recorremos a uma revisão bibliográfica assistemática nos Anais de três eventos de design e design de moda brasileiros: P\&D, Moda Documenta e Colóquio de Moda. Tanto o P\&D quanto o Moda Documenta disponibilizam online apenas os Anais das três últimas edições, por isso, esse foi o recorte utilizado para todos os eventos. No total foram levantados 12 artigos que relacionaram design de superfície à gênero, de alguma forma.

\section{Desenvolvimento}

Registros de práticas tidas como arte, artesanato e outro tipo de design foram mais comuns do que aqueles considerados especificamente design de superfície. Como dito anteriormente, o entendimento acerca design de superfície nesse artigo considera criação, projeto e produção que envolva superfícies. Apresentaremos alguns textos encontrados em revisão bibliográfica sistemática com o objetivo de problematizar a relação do design com as questões de gênero.

Buckley (1986) afirma que a presença das mulheres na história do design se dá de diversas maneiras, sejam como profissionais, teóricas, consumidoras, historiadoras ou objetos de representação. A autora analisa a presença do patriarcado nas estruturas sociais e afirma que essa construção social agiu de forma consciente na exclusão das mulheres da história da sociedade e da história do design. Para ela, o design e o lugar das mulheres no design foram determinados dentro de um contexto patriarcal que estabelece os lugares, papéis, comportamentos e profissões adequados para mulheres e para homens.

A autora explicita métodos historiográficos específicos que são compostos de seleção, classificação e priorização de tipos de design e de designers, de estilos e movimentos característicos e diferentes modos de produção, a serviço de ignorar e excluir a participação das mulheres da história do design. Como exemplo cita alguns livros publicados entre 1975 e 1980: o "Pioneers of Modern Design: From William Morris to Walter Gropius" de Nikolaus Pevsner, o "Theory and Design in the First Machine Age" de Reyner Banham, o "Industrial Design" de John Heskett, os quais afirma serem livros básicos sobre a história do design, nos quais poucas mulheres são citadas. Buckley (1986) apresenta em seu contexto britânico, o tema que emergiu na história do design da época: o papel das mulheres e do design.

Para discutir o tema, Buckley (1986) dialoga com Parker e Pollock e o livro "Old Mistresses: Women, Art and Ideology", no qual a forma como a história da arte é escrita é questionada. As autoras entendem que é preciso expor os "valores, pressupostos, silêncios e preconceitos" para entender como as artistas são retratadas e assim, compreender a definição de arte e artista na sociedade a qual elas pertencem. Nesse registro, Buckley (1986) apresenta outra questão quando se trata da relação entre os temas, mostra que os tipos de fontes em pesquisas com o tema mulheres e design, costumam ser fontes orais de mulheres para contar suas histórias, também identificando o trabalho doméstico e as atividades não profissionais como áreas importantes a 
serem registradas e contrastarem com a "documentação oficial" da época.

Buckley (1986) faz um recorte sobre a ação do patriarcado em todos os setores do design, mostrando que os resultados dos estereótipos femininos circunscrevem as oportunidades das mulheres, determinando certas ocupações e papeis sociais como femininos e menos valorizados do que às atividades determinadas aos homens. Sua aplicação no design vem com o exemplo do status do design industrial ser maior do que o do design têxtil. Nesse momento, a autora apresenta o binômio cultura e natureza, explicando que em uma sociedade industrial avançada, a cultura tem valor mais elevado do que a natureza, e os papeis masculinos são vistos mais como pertencentes à cultura do que a natureza, e os papeis femininos em oposição, vistos como mais pertencentes à natureza. Vinculando à capacidade biológica de reprodução das mulheres, uma justificativa para que sejam vistas mais compatíveis com a natureza.

De forma crítica, Buckley (1986) mostra que o conceito de determinismo biológico aplicado ao design, naturaliza habilidades como uma consequência do sexo, como capacidades inatas. Resultando em as mulheres sendo consideradas como mais meticulosas, decorativas e a elas sendo adequadas as áreas das artes decorativas, nas quais estão incluídas as confecções de jóias, bordados, design gráfico, crochê, tricô, cerâmica e costura. A autora cita o casal Sonia e Robert Delaunay como exemplo de práticas sociais que reforçam os estereótipos e noções de diferentes características para homens e para mulheres, quando definem Sonia como tendo "um bom instinto" para o uso da cor em suas produções, enquanto que Robert é considerado um profissional com uma "boa teoria da cor formulada".

Outro argumento apresentado por Buckley (1986) como central para uma crítica feminista sobre a história do design é que haja um exercício no sentido de redefinir o que constitui design. Em diálogo com Penny Sparke (1984), a autora apresenta que a "história do design é o estudo da produção em massa de objetos", dessa forma excluindo a produção artesanal e consequentemente a produção das mulheres. Buckley (1986) ressalta que essa produção deve ser problematizada e contextualizada que não era realizada por causas biológicas, naturalizadas, mas sim porque para muitas mulheres esse modo de produção era a única maneira possível, uma vez que elas não tinham acesso nem às fábricas, muito menos ao conhecimento oferecido em escolas de design. $O$ trabalho manual além de permitido, também era uma oportunidade para que as mulheres expressassem suas habilidades artísticas de formas criativas fora da profissão design, entendida como dominada pelos homens.

Simioni (2007) em seu artigo sobre a artista Regina Gomide Graz, aborda questões similares às de Buckley (1986), no âmbito da história da arte intenta discutir a dimensão do gênero com foco nas obras de artes têxteis. Pelo estudo de caso, Simioni (2007) mostra como a disciplina, assim como o design, também se baseia em relações de hierarquia entre os objetos. No contexto modernista, Graz teve que negociar sua posição pois produzia arte aplicada em suporte têxtil, o que era duplamente depreciado. Por ser socialmente considerada pertencente à arte "feminina" e ser realizada em suporte artístico menos valorizado do que os tradicionais (pintura e escultura). A autora, assim como Buckley (1986), também dialoga com Griselda Pollock (1994) para problematizar questões de gênero na história da arte.

Simioni (2007, p.91), contextualiza os anos 1970 como sendo um período no qual o movimento feminista dentro da história da arte estava se atendo à questão da ausência de nomes de mulheres nos registros dos cânones artísticos, e justificando que esse fato não era relacionado a 
"ausências naturais de qualidades intelectuais ou artísticas", mas a uma prática similar à que Buckley (1986) nos apresentou no design, de exclusão "mais ou menos institucionalizada" de mulheres do campo artístico. Aqui se repetia o movimento britânico, as mulheres não eram aceitas nas escolas, nesse caso, nas academias de belas artes.

Como as mulheres não tinham acesso às aulas de modelo vivo, suas posições estavam prédeterminadas a práticas artísticas "menores", como afirma a autora. Simioni $(2007$, p.94) as apresenta: "os retratos, as miniaturas, as pinturas em porcelana, as pinturas decorativas (vãos, esmaltes, etc.), as aquarelas, as naturezas-mortas e, finalmente, toda a sorte de artes aplicadas, particularmente as tapeçarias e bordados". A autora explicita, então, o círculo vicioso de dupla desvalorização. Com o tempo esses gêneros foram sendo considerados femininos, logo, as obras tidas como de menor valor naturalmente tinham como origem "práticas artísticas femininas". Portanto, durante o século XIX: "as mulheres, seres intelectualmente inferiores, eram vistas como capazes de realizar apenas uma arte feminina, ou seja, obras menos significativas do que aquelas feitas pelos homens geniais: as grandes telas e esculturas históricas".

A autora explicita que neste entendimento de obras mais significativas também estava presente a tradição de considerar "grandes" artes aquelas com habilidades técnicas baseadas "no disegno: a pintura, a escultura e a arquitetura", no planejamento e no trabalho intelectual; enquanto que as outras artes nas quais o domínio do desenho não era uma obrigação, receberam valor negativo, por terem mais características manuais (SIMIONI, 2007, P.94).

Como exemplo dessa dupla desvalorização, Simioni (2007, p.95) traz o caso da Bauhaus de Weimar, época na qual as mulheres tiveram suas participações em certos ateliês da escola dificultadas. Os ateliês de arquitetura e de pintura, considerados mais significativos, por pertencerem às grandes artes, não possuíam alunas, enquanto que, o ateliê de tecelagem, pertencente às artes menores, era "praticamente frequentado com exclusividade pelo sexo feminino".

A autora enfatiza que todo esse processo por ela descrito deve servir para a compreensão de que as práticas têxteis foram sistematicamente desvalorizadas, assim como as práticas femininas a elas vinculadas. Importante ter ciência de toda essa estrutura e problematizar a naturalização desses estigmas. Em diálogo com Becker (1982), ressalta que a ideia de negociação de trabalho, vem da compreensão de que: "por mais que enfrentassem obstáculos concretos para se firmarem como artistas, possuíam capacidade de intervir, modificar e mesmo recriar sua própria condição dentro de um contexto determinado", mostrando dessa forma a capacidade de ação e articulação de algumas artistas.

Kaygan (2016), autora feminista, apresenta uma crítica à relação entre gênero, tecnologia e o trabalho de designer. A autora explicita duas vertentes de representações das mulheres no design: a designer "excepcional" que foi negada pela história do design e a designer que tem um ponto de vista único e especializado no cuidado com a usuária de um projeto de design.

A autora critica as dicotomias entre os gêneros masculino e feminino (público/privado, duro/macio, função/forma, industrial/doméstica) e afirma que essas questões estão presentes na cultura e na sociedade ocidental industrial nas áreas de trabalho do design. Kaygan (2016) mostra a assimetria de valor e poder, na qual maiores remuneração, status, fatores tecnológicos e industriais são atribuídos ao gênero masculino, inclusive no âmbito do design. 
Em breve panorama histórico, a autora apresenta recortes de estudos feministas e suas discussões, destacando-se para o presente trabalho, a busca pela desconstrução da naturalização das divisões dualistas, pretendendo esclarecer que se tratam de construções sociais injustas. Dessa forma, Kaygan (2016) objetiva situações de menor desigualdade entre os gêneros nas práticas de design.

Santos (2015) possui relação com algumas das questões apresentadas acima, em seu texto sobre Georgia Hauner e a empresa de móveis Mobilinea. No qual tensiona aspectos interessantes para a presente pesquisa, como: as formas convencionais pelas quais a história do design é contada e o apagamento da presença das mulheres dessa história. Em diálogo com Brenda Martin e Penny Sparke (2003), a autora confirma o que Buckley (1986) nos afirmara no início deste item, que as mulheres possuem diferentes maneiras para participarem da "atividade de design, seja como produtoras e consumidoras, mas também como clientes, colaboradoras e comentaristas" (SANTOS, 2015, P.28).

Procurando modificar a maneira pela qual se olha para o design, Santos (2015) se filia a Campi (2003) para desconstruir o conceito de que o protagonismo dos designers deve ser enfatizado, uma vez que essa narrativa prioriza um indivíduo e invisibiliza os demais atores sociais envolvidos. Como também problematizar outro protagonismo, o da dimensão da produção nos processos design, as autoras entendem que essa maneira de ver o design, privilegia o gênero masculino. Dado que historicamente, às mulheres eram permitidas as práticas de menor valor, geralmente relacionadas às dimensões de consumos e usos.

A autora se filia aos estudos pós-estruturalistas, para quem a relação sexo-gênero é desconstruída, Santos (2015, p. 27-8) explica a relação hierárquica na qual a dimensão da produção tem mais valor do que as dimensões dos consumos e usos a partir da categoria gênero. Para a autora, a categoria gênero é entendida como "um conjunto de normas, discursos, práticas e materialidades que operam na naturalização de noções de feminilidades e masculinidades culturalmente construídas", dessa forma adensa o debate proposto até o momento na presente pesquisa.

A autora complementa sua definição de gênero com a afirmação de Judith Butler (2003) de que seus efeitos "são incorporados e produzem não só a sensação de estabilidade dos sexos, como também prescrevem limites para interesses e comportamentos atribuídos a mulheres e homens". Dessa forma, Santos (2015) traz Hollows (2008) e finaliza seu argumento da hierarquia entre as dimensões produção, consumo e uso, pois o gênero atribui à primeira o conceito de esfera pública e às demais o conceito de esferas privadas, respectivamente tidas como pertinentes ao gênero masculino e feminino.

Para Santos (2015, p.42) é indiscutível que questões de gênero devem ser consideradas quando em pesquisas cujo tema é relativo à pouca presença de registros sobre mulheres na história do design. Partindo da categoria gênero, a autora concorda com Rubino (2010), que as relações de poder e hierarquia são permeadas por naturalizações assimétricas nas quais artefatos e práticas são classificadas como "especificamente masculinos ou femininos" e, consequentemente, considerados como sendo de maior ou menor valor. Santos $(2015$, p.42) finaliza seu artigo afirmando considerar fundamental a problematização dos binarismos como "público e privado; produção e consumo; especializado e amador; erudito e popular; design e artesanato", para que uma nova forma de historiografia sobre a participação das mulheres no design moderno brasileiro possa ser proposta e 
contada.

A partir deste momento, apresentaremos alguns artigos encontrados na revisão bibliográfica assistemática. De um total de doze trabalhos, dez tratam de práticas têxteis, um de produção cerâmica e um de design de interiores. A maioria dos trabalhos apresentam práticas pertencentes às práticas do design de superfície, e dialogam com o conteúdo discutido anteriormente, pois tratam dos temas: historiografia do design e apagamento de mulheres; naturalização de papeis como especificamente femininos ou masculinos; binômio cultura versus natureza; definição usual do que é considerado design excluindo mulheres e sua produção; artes decorativas como artes femininas e espaços nos quais as mulheres tinham acesso; e dicotomias e assimetrias de valor e poder gerando desigualdade social entre os gêneros.

Três deles discutem conteúdo relacionado a design de superfície e trabalho de mulheres, com ênfase no ensino, no aprendizado de técnicas e práticas. Almeida, Silva e Paschoarelli (2012) discutem sobre o ensino de práticas têxteis na Bauhaus e abordam a questão do direcionamento das mulheres para a oficina de tecelagem, como já comentado no texto de Simioni (2007). Reinheimer (2016) apresenta a trajetória da artista e designer de moda Olly Reinheimer e o projeto de formação artística no MAM-RJ. Também sobre a formação artística, relacionada a design têxtil e de moda realizada em museu, porém no MASP, Scarpa e Kanamaru (2016).

Quatro artigos abordam assuntos relacionados ao design de superfície e trabalho de mulheres, como forma de registro de trabalhos, e não necessariamente problematizam suas relações, apenas as apresentam. Stahn e Pazmino (2012) realizam um levantamento histórico das rendas de bilro no Brasil, comentam sobre as práticas das mulheres rendeiras porém não se aprofundam em outras problematizações como as que pudemos notar nos textos da revisão bibliográfica sistemática. Cestari et al (2014) registram processos de produção artesanal cerâmica e a nova dinâmica de trabalho marcada pelo gênero, situação na qual é possível ver o tema de naturalização dos papeis. Maynardes (2016) e Morgado e Simili (2015) abordam questões relacionadas a domesticidade, o primeiro discorre em parte sobre as normas que as mulheres deveriam seguir; e o segundo fala sobre os têxteis domésticos como acervo.

No presente trabalho, destacaremos produções que enfatizam tensionamentos existentes nas relações entre design de superfície e trabalho de mulheres. Almeida, de Almeida e Held (2012) trata do mesmo objeto de estudo em 2016, de forma mais elaborada, portanto optamos por abordar seu trabalho mais recente. Almeida (2016) em seu texto busca entender como as artesãs convivem e lidam com seu trabalho, a produção do bordado na cidade de Passira, em Pernambuco. A autora vê na tradição da produção artesanal do bordado manual uma forma de resistência dessas mulheres. A partir de entrevistas realizadas pela pesquisadora com um grupo de bordadeiras integrantes da Associação das Mulheres Artesãs de Passira (AMAP), percebeu-se a maneira pela qual os processos envolvidos na atividade de bordar estão "relacionados com as artesãs e com contextos sociais" em que estão inseridas. Esse ofício "amplamente presente na vida das mulheres e fundamental para sua sobrevivência naquele contexto", por ser transmitido de geração em geração (ALMEIDA, 2016, P.15).

As artesãs fundaram a associação no ano de 2008 para "encontrar soluções para problemas socioeconômicos" das mulheres, "promover intercâmbio de experiências profissionais" e "representar a classe junto aos órgãos governamentais e privados" (ALMEIDA, 2016, P.16). Somado aos motivos e objetivos das artesãs se organizarem, a autora apresenta dados do IBGE (2007:94) 
mostrando que o bordado é a atividade artesanal presente em $75,4 \%$ dos municípios brasileiros, se tornando assim a mais representativa no país. Segundo as entrevistadas, a história do bordado e da cidade de Passira possuem origens simultâneas, e essa atividade manual é fonte de renda das famílias que ali residem, além de ser um "atrativo turístico" que gera interesse sobre Passira (ALMEIDA, 2016, P.17). No presente trabalho consideramos o fazer têxtil e a ornamentação de superfícies como pertinente à disciplina do design de superfície, dessa forma a pesquisa de Almeida (2016) contribui para reflexão sobre um conhecimento técnico do design de superfície - o bordado - sendo tido como um fazer exclusivamente feminino na cidade de Passira. Esse fazer como se pode ver pelos dados do IBGE é representativo no Brasil, fato também de interesse neste trabalho.

Além disso, o artigo apresenta e ressalta a importância que o fazer tem para as bordadeiras, o que pode ser notado em falas nas quais enfatizam o fato de que elas "tiram sustento do bordado" e dão destaque "as coisas que conseguiram por meio do bordado" (ALMEIDA, 2016, P.23). Mais do que isso, o fazer dessas mulheres é uma "experiência coletiva, da forma como as pessoas se ligam entre si" (ALMEIDA, 2016, P.16), transmitido pela tradição oral e pela observação das artesãs mais experientes.

As mulheres de Passira declaram o "orgulho de manter financeiramente a família com o seu trabalho", e esse orgulho é maior pois é também "por meio de uma atividade que faz parte de sua própria história" que as artesãs o realizam (ALMEIDA, 2016, P.23). Elas relatam que "não conseguem parar de bordar e que nasceram para isso", dessa forma o "bordado adquire uma significação em suas vidas, um aliado que as ajuda a seguir e a suportar as adversidades" (ALMEIDA, 2016, P.24). 0 fato das artesãs de Passira se entenderem como nascidas para isso e atuarem em uma atividade historicamente considerada menor, na maneira como a história do design é comumente contada, se faz importante neste trabalho, pois a complementação seguinte de que a prática dá significado às suas vidas como uma forma de resistência e superação é considerada uma reflexão significativa.

Melo e Amadori (2016), pesquisadoras com formação em design para estamparia têxtil e design de superfície, também abordam o tema do trabalho têxtil com foco em uma comunidade, no caso delas, a etnia Mapuche. Com o objetivo de demonstrar aspectos socioculturais da etnia, as pesquisadoras selecionaram os processos de fazer do poncho (makuñ) e da faixa (chamallwe e tarüwe), produtos-chave para esse povo. A etnia Mapuche é ameríndia e vive no sul da América do Sul, entre as regiões andinas do Chile e da Argentina. As pesquisadoras explicam que mesmo a etnia tendo passado por transformações em seus modos de vida, sua relação com o tear e a tecelagem é uma constante. Segundo as autoras, os tecidos tinham diversas significações e funções, como moedas de troca e símbolo de status, formas de abrigo e proteção, e vestimentas.

Melo e Amadori (2016) em diálogo com Alvarado (2002) apresentam as tecedoras como especialistas e ressaltam a relevância e o papel delas na identidade dos povos andinos:

A prenda têxtil representa um meio artístico imprescindível na representação de uma identidade cultural. Todo artefato realizado por uma especialista tecedora passa a formar parte de uma poderosa rede de relações sociais e simbólicas que fazem possíveis a vigência de uma cultura. Busca-se fundamentalmente, cobrir um suporte em um gesto e uma ação estética, convertendo o tecido em um diferenciador cultural. Assim, os têxteis se transformam em artefatos para o adorno, criados e produzidos para a ostentação e o luxo (ALVARADO, 2002, apud Melo e Amadori, 2016).

Os artefatos têxteis comunicam a importância social de quem os veste, os símbolos desenhados a partir da tecelagem os (as) identificam, o trabalho das especialistas tecedoras possui 
relação direta com a identidade cultural do povo Mapuche. O conhecimento sobre o desfiar da lã, sobre os elementos da natureza a serem utilizados para tingimento natural, o planejamento do desenho e a confecção no tear resultam na peça de vestuário, mas também expressam "sua própria culturalidade" (MELO; AMADORI, 2016, P.44).

Além do trabalho da tecelagem ser dividido por gênero, somente mulheres o realizando, as autoras trazem na apresentação do poncho e da faixa a divisão do artefato por gênero. $O$ poncho Mapuche criado e confeccionado por mulheres, apenas pode ser usado por homens, com a especificidade também de hierarquia nos usuários. Dependendo das cores, gramatura do tecido e seus desenhos, ele é recomendando para o trabalho (tecido grosso e simples) ou para ocasiões especiais (mais luxuosos), para um guerreiro ou para um membro da nobreza. As faixas são separadas por gênero, sendo que a chamallwe é usada pelos homens na cintura por cima da calça enquanto que a faixa para mulheres é a tarüwe indicada para amarrar seus vestidos.

$\mathrm{O}$ artigo de Melo e Amadori (2016) auxilia na discussão vinculando os temas design de superfície e gênero pois além da produção têxtil Mapuche ser considerada como pertencente ao design de superfície, as autoras mostram o trabalho como especificamente feminino e os significados existentes nele. Significados esses muito valiosos para a sociedade Mapuche e pelos quais as mulheres são responsáveis. As especialistas tecedoras conseguem estabelecer um diálogo com os membros da sociedade Mapuche a partir do seu modo de expressar nessa "existência de uma linguagem própria", contando histórias, memórias das tecedoras "através dos desenhos empregados em uma determinada peça". As peças têxteis são entendidas como "suporte da mensagem" a ser transmitida, e o valor da indumentária a torna também símbolo "de sua existência" (MELO; AMADORI, 2016, P.47-8).

Lenzi (2016) tem como tema de pesquisa as rendas de bilros em Peniche, Portugal, arte considerada Patrimônio Cultural da cidade, utilizando a observação participante como procedimento, buscou compreender as relações existentes entre o artefato e suas práticas com os (as) habitantes da cidade. Seu foco foi principalmente as "mulheres, detentoras e guardiãs dessa sabedoria". A autora apresenta o contexto do local, contando que nessa cidade pequena os homens iam para o mar "em busca de sustento, as mulheres, que ficavam em terra com os filhos, faziam rendas de bilros" (LENZI, 2016, P.25-26). A prática de confeccionar as rendas de bilro servia como uma complementação da renda familiar e também como um momento de interação social entre as mulheres da cidade, e assim, a espera do retorno de seus maridos, pais e filhos ficava "mais leve" (LENZI, 2016, P.26).

A autora recorre à Calado (2003, p.113) para complementar que a reunião das portuguesas de Peniche se dava em momentos específicos: "[...] seriam milhares as mulheres penicheiras que, nas horas em que as lides domésticas lhe permitiam, se dedicavam ao trabalho da almofada [...]", somente quando realizadas as tarefas domésticas, as mulheres podiam se encontrar e desenvolver outras práticas de e entre mulheres. Calado (2003, p.113) completa: “[...] num recanto qualquer de suas casas ou ao ar livre, nos quintais ou à soleira das portas, em pequenos grupos de vizinhas, trocando experiências [...]", fosse por entretenimento ou por objetivar renda complementar, as mulheres se reuniam e muitas se tornavam rendilheiras (LENZI, 2016, P.27).

Buscando uma possível origem histórica da prática em Peniche, Lenzi (2016) continua em diálogo com Calado (2003, p.85) e apresenta a seguinte afirmação: "independente da hipótese correta, todas elas contribuíram fortemente para o desejo natural das mulheres por essa artesania". 
Lenzi (2016) completa dizendo que como existem documentos que provam a prática sendo ensinada de mãe para filha, e "que sua essência nasce do feminino" (LENZI, 2016, P.30). Neste trabalho entendemos como problemático o posicionamento de essencializar ou naturalizar saberes e fazeres como especificamente femininos.

A autora segue destacando a importância das rendas de bilros como formadoras da identidade cultural das mulheres de Peniche e argumenta a questão da reciprocidade entre as portuguesas desse local e as rendas de bilros afirmando que "uma não viveria sem a outra, ambas se complementam, agregam-se e renascem juntas" (LENZI, 2016, P.31). Lenzi mostra que com o passar do tempo, o ofício tornou-se uma "aprendizagem pedagógica e metodológica" e que foram criadas as escolas de bilros, nas quais as garotas com idade até dez anos eram ensinadas o conhecimento técnico de se fazer renda; como também outros conhecimentos como "o saber ler, escrever, realizar cálculos, a doutrina católica, entre outros", por professoras e diretoras mulheres (LENZI, 2016, P.31).

Lenzi (2016) contou a história do povo de Peniche, "cujas protagonistas são as mulheres e as rendas de bilros". No final de seu artigo, relata a autonomia presente na vida das mulheres rendeiras que, sozinhas por muito tempo, tomavam decisões sobre as vidas de seus filhos, eram responsáveis por sustentá-los e alimentá-los, e "aos poucos, empodeiravam-se de sua própria vida e independência" (LENZI, 2016, P.37). Novamente a autora ressalta o fato de que as mulheres se uniam e ainda se unem, são "parceiras e cúmplices de rendas e delas mesmas", a autora considera a renda "um belo pretexto para reconhecer-se identitária e socialmente como mulher empodeirada, independente e forte, diante de toda e qualquer dificuldade" (LENZI, 2016, P.38).

Esse artigo ajuda a refletir sobre design de superfície e gênero pois novamente se trata de uma prática relacionada ao design têxtil, portanto considerada pertencente ao design de superfície. No decorrer do texto, a autora perpassa por alguns temas interessantes a serem discutidos como naturalização de papeis femininos e masculinos, divisão sexual do trabalho, artes decorativas como artes femininas, e a existência de um movimento das mulheres se organizando e mudando uma prática considerada de menor valor (apenas um complemento de renda, no início) para uma prática que demonstra força e independência.

Nos três textos acima, de Almeida (2016), Melo e Amadori (2016) e Lenzi (2016), foi possível ver em comunidades diferentes o ensino, o aprendizado e a tradição da arte têxtil, relacionados às práticas de mulheres e divisões de trabalho por gênero. No texto a seguir, é possível problematizar definições sobre design de superfície, ornamento, têxtil, além de tensionar conceitos de gênero.

França (2016) buscou analisar em seu artigo exemplos de designs têxteis que trabalhassem de forma diferente dos padrões normativos de gênero no início do século XXI. A autora utiliza Rüthschilling (2008, p.31) para definir design têxtil como pertencente ao design de superfície, considerado a "maior área de aplicação do design de superfície", e explica que sua criação pode se expressar através de diversas técnicas, sendo elas: tecelagem, malharia, tinturaria, estamparia e bordado. Ao apresentar o status que o design têxtil possui, aos olhos de alguns designers e arquitetos, a autora diz que a associação do têxtil com decoração e ornamentação e a consideração dos mesmos como "algo sem seriedade, frívolo e banal", de acordo com Schneider (2010) tem como origem histórica a lógica do Modernismo e de sua perspectiva funcionalista. No início do século XX, alguns de seus membros consideravam de maior valor as funções práticas dos produtos do que as funções estéticas. 
França (2016) cita o ensaio "Ornamento e Crime" de Loos (1908) no qual o ornamento era visto como "força de trabalho e material desperdiçados", e na sequência se posiciona contra essa linha de pensamento, afirmando que a intenção de seu artigo é justamente "refutar a ideia de que o design têxtil é algo dispensável ou até mesmo desperdício" (FRANÇA, 2016, P.65-6). França (2016) também questiona o caráter neutro do design ao argumentar que a perspectiva negativa sobre a ornamentação e o design têxtil demonstra a incoerência dessa afirmação.

No artigo, o design é considerado mediador das relações sociais, agindo tanto nas transformações sociais quanto sendo transformado por elas, a autora explica que o design compõe o fenômeno social, materializa e compartilha suas ideias e valores. A pesquisadora conversa com autores da cultura material e se filia à Miller (2009), ao dizer que os artefatos não são representações daquilo que as pessoas têm em seus interiores, eles são participantes do processo pelo qual as pessoas "criam a si mesmas" (FRANÇA, 2016, P.71).

Outro tema que a autora busca questionar é a naturalização sobre os gêneros, seu posicionamento é de contribuir para "posturas de autoaceitação, tolerância, empatia, inclusão e respeito em relação à diversidade das subjetividades" e sua análise se dá em casos nos quais os designs têxteis auxiliem na mudança de padrões de gênero. França (2016) em diálogo com Hall (2007) adiciona a questão de identidade ao se pensar designs têxteis como artefatos que se relacionam e fazem parte das relações sociais, participam na construção e reconstrução das pessoas de "suas subjetividades e identidades" (FRANÇA, 2016, P.67 e P.71).

A autora adere ao conceito de gênero de Santos (2010) e o entende como sendo um "conjunto de discursos e práticas que constroem e reformulam limites para os sexos", e recorre a Butler (2008) para complementar que considera o gênero como um "processo cultural que se renova continuamente". Dessa maneira a autora se posiciona a favor dos conceitos "mulheres" e "homens" como "significados múltiplos e dinâmicos tecidos no contexto cultural, político, econômico, religioso e científico de um tempo e lugar", como forma de abranger polissemias. (FRANÇA, 2016, P.73). Para realizar sua análise, a autora apresenta as "ideologias de gênero" que historicamente se tornaram "naturalmente" pertinentes às mulheres e aos homens ocidentais no que diz respeito a padrões de comportamentos e características de indivíduos daquele gênero e de que forma eles são representados e materializados em peças de design têxtil. Sendo elas, para as mulheres: "ideias de doçura, beleza, fertilidade, subjetividade sentimental e delicadeza", materializadas em tecidos com "cores pastéis", referências de animais e florais, além de "laços e corações", por exemplo.

Enquanto que para os homens: "força, virilidade, poder, coragem e razão", características materializadas em "tecidos opacos, foscos, mais pesados, desgastados", com motivos e "estampas geométricas (listras, xadrezes), com estampas miúdas, monocromáticos, com cores 'discretas' e com menos vivacidade como castanhos, acromáticos, verdes, azuis, bordôs e etc". Essas "ideologias" estruturadas em relação de oposição possuem hierarquia, sendo que os conceitos vinculados às masculinidades são considerados superiores e às feminilidades inferiores, por exemplo, razão mais valorizada que emoção, força mais valorizada que fragilidade (FRANÇA, 2016, P.74-5).

França (2016) mostra como a naturalização de certos saberes como de e para mulheres foi construída e reproduzida historicamente. Para tanto, apresenta dados de Carvalho (2008, p.89) sobre o século XIX, em que a: 
suposta aptidão feminina para detalhes seria cultivada desde a infância pelo exercício comparativo entre objetos usados como elementos de decoração. As mulheres colecionavam miudezas, bibelôs, com os quais formavam o 'gosto artístico', comparando formas, cores, texturas e materiais. (Carvalho, 2008, p.89)

O trabalho manual exercido no ambiente doméstico, a criação "artística e artesanal" com "valorização dos aspectos estéticos das superfícies" era usual e repleta de técnicas mais presentes no universo feminino do que no universo masculino, como "crochês, bordados, rendas e estampas pintadas a mão" (FRANÇA, 2016, P.76).

Compreender design como componente da mediação social, dialogando com conceitos da cultura material e Daniel Miller; buscar refletir sobre a naturalização de práticas como vinculadas a determinado gênero e dialogar com Marinês Ribeiro dos Santos; acessar Adrian Forty e Vânia Carneiro de Carvalho para tensionar conceitos de design e artefatos vinculando à questão de gênero; refletir sobre os processos históricos que vincularam o design de superfície ao trabalho das mulheres e ao conceito de frivolidade, são convergências entre o artigo de França (2016) e o entendimento sobre as relações entre design de superfície e trabalho de mulheres no presente trabalho.

\section{Conclusão}

Este artigo tratou do levantamento de produção acadêmica que tem design de superfície e o trabalho de mulheres como objeto de pesquisa, ao final foi possível notar algumas questões. A primeira se refere a uma ausência de objetos de pesquisa que se aprofundem nas relações entre os temas, uma vez que a maioria não denomina como design de superfície algumas práticas consideradas neste trabalho como a ele pertinentes. Como por exemplo, tecelagem, malharia, tapeçaria e bordado. Foram encontrados 2.758 artigos que discorrem sobre design de superfície, que por vezes denominam as práticas, as técnicas e tecnologias, porém, em sua maioria, com ausência de reflexão sobre os indivíduos que as realizam.

A segunda questão é a pouca presença de produção que tenha como objetivo problematizar protagonismo e questões de gênero presentes em práticas de trabalho de mulheres no design de superfície. Na maioria das produções encontradas, essas questões foram apenas citadas ou mostradas como uma apresentação de sua existência, mas não analisadas ou discutidas.

Os temas design de superfície e trabalho de mulheres poderiam estar presentes em mais produções acadêmicas, problematizando algumas questões como o status negativo relacionado aos trabalhos manuais artísticos e domésticos, localizando historicamente a origem desse estigma, refutando o entendimento da ornamentação e atividades relacionadas como frívolas e menores por serem práticas de e para mulheres, mostrando como a naturalização de papeis de gênero pautaram práticas, comportamentos e características de forma hierárquica e desigual.

Há uma carência de análises sobre a relação do design de superfície brasileiro e o trabalho de mulheres na área, logo, se faz importante documentar, descrever e analisar essas presenças e praticas, auxiliando em promover tanto diferentes perspectivas sobre a participação das mulheres na história do design brasileiro, quanto uma nova forma de compreensão sobre o design no Brasil.

\section{Referências}


ALMEIDA, A. J. M. Bordado e resistência: a produção artesanal no nordeste brasileiro. In: MODA DOCUMENTA: Museu, Memória e Design 2016. Anais do 3o. Congresso Internacional de Memória, Design e Moda. São Paulo: Estação das Letras e Cores Editora, Ano III. v. 01, 2016, [p. 15 - 24].[ISSN: 2358-5269]

ALMEIDA, A. J. M; HELD, M. S. B. de. Os caminhos da atividade artesanal: bordados Passira e o recente contato com a moda nacional. In: 10o Congresso Brasileiro de Pesquisa e Desenvolvimento em Design, São Luís, 2012. Anais do 10o Congresso Brasileiro de Pesquisa e Desenvolvimento em Design, de 10 a 13 de outubro 2012, São Luís. p. 8404.

ALMEIDA, M. D. de; SILVA, J. C. P. da; PASCHOARELLI, L. C. O ensino na Bauhaus e uma observação sobre a oficina têxtil. In: 10o Congresso Brasileiro de Pesquisa e Desenvolvimento em Design, São Luís, 2012. Anais do 10o Congresso Brasileiro de Pesquisa e Desenvolvimento em Design, de 10 a 13 de outubro 2012, São Luís. p. 3904.

BUCKLEY, C. Made in Patriarchy: Towards a feminist analysis of women and design. PAD: Pages on Art and Design, 8, 1986. ISSN 1972-7887. Disponível em: < http://dx.doi.org/10.2307/1511480/ >. Acesso em 15 abr. 2017

CESTARI, G. A. do V; GUIMARÃES, M. J. S; CARACAS, L. B; SANTOS, D. M. Saberes tradicionais e interações na produção de artefatos cerâmicos na comunidade quilombola de Itamatatiua - MA. In: 11o Congresso Brasileiro de Pesquisa e Desenvolvimento em Design, Gramado, 2014.

CONFORTO, E. C.; AMARAL, D. C.; DA SILVA, S. L. Roteiro para revisão bibliográfica sistemática: aplicação no desenvolvimento de produtos e gerenciamento de projetos. $8^{\circ}$ Congresso Brasileiro de Gestão de Desenvolvimento de Produto, Porto Alegre, 2011.

FRANÇA, M. S. Design Têxtil: memória das subversões dos limites de gênero no início do século XXI. In: MODA DOCUMENTA: Museu, Memória e Design 2016. Anais do 3o. Congresso Internacional de Memória, Design e Moda. São Paulo: Estação das Letras e Cores Editora, Ano III. v. 01, 2016, [p. 65 - 79].

KAYGAN, P. Gender, Technology, and the Designer's Work: A Feminist Review. Design and Culture, 2016. Disponível na internet por http em: <10.1080/17547075.2016.1172862 >. Acesso em 15 abr. 2017

LENZI, G. P. Entre terra e mar: a identidade cultural de Peniche trançada pelos bilros. In: MODA DOCUMENTA: Museu, Memória e Design 2016. Anais do 3o. Congresso Internacional de Memória, Design e Moda. São Paulo: Estação das Letras e Cores Editora, Ano III. v. 01, 2016, [p. 25 - 40].[ISSN: 2358-5269]

MAYNARDES, A. C. A casa, o lar e o mobiliário. In: 12o Congresso Brasileiro de Pesquisa e Desenvolvimento em Design, Belo Horizonte, 2016. Anais do $12^{\circ}$ Congresso Brasileiro de Pesquisa e Desenvolvimento em Design, de 4 a 7 de outubro 2016, Belo Horizonte.

MELO, F. M. de; AMADORI, M. P. A produção têxtil dentro da cultura Mapuche. In: MODA DOCUMENTA: Museu, Memória e Design 2016. Anais do 3o. Congresso Internacional de Memória, Design e Moda. São Paulo: Estação das Letras e Cores Editora, Ano III. v. 01, 2016, [p. 41 - 50].[ISSN: 2358-5269]

MORGADO, D. P; SIMILI, I. G. Têxteis domésticos de quarto e cozinha: memórias e reaproveitamento. In: 11o Colóquio de Moda - 8o Edição Internacional. 2o Congresso Brasileiro de 
Iniciação Científica em Design de Moda. 2015. Anais do 110 Colóquio de Moda - 8o Edição Internacional. 2o Congresso Brasileiro de Iniciação Científica em Design de Moda. 2015.

PEREIRA, R. M. Construção e design de guitarras nos anos 1960 e 1970: narrativas sobre trabalho e trajetórias em São Paulo - SP e Porto Alegre - RS. 2014. 145p. Dissertação (Mestrado em Design)

- Programa de Pós Graduação em Design, Universidade Federal do Paraná, Curitiba. 2014.

POLLOCK, Griselda. Vision \& difference: feminity, feminism and the histories of art. Londres: Routledge, 1994

REINHEIMER, P. O design de moda e a construção de uma modernidade brasileira. In: MODA DOCUMENTA: Museu, Memória e Design 2016. Anais do 3o. Congresso Internacional de Memória, Design e Moda. São Paulo: Estação das Letras e Cores Editora, Ano III. v. 01, 2016, [p. 96 - 113].[ISSN: 2358-5269]

RUBINO, Silvana. Corpos, cadeiras, colares: Charlotte Perriand e Lina Bo Bardi. Cadernos Pagu [online]. 2010, n.34, pp.331-362. ISSN 1809-4449.

SANTOS, Marinês Ribeiro dos. 2015a. Questionamentos sobre a oposição marcada pelo gênero entre produção e consumo no design moderno brasileiro: Georgia Hauner e a empresa de móveis Mobilinea (1962-1975). Caderno a Tempo: Histórias em arte e design. Barbacena: EdUEMG, vol.2, 2015, p.25-45.

SCARPA, S. P; KANAMARU, A. T. O design têxtil e de moda no MASP entre os anos 1950 e 1953. In: 12o Colóquio de Moda - 9o Edição Internacional. 3o Congresso Brasileiro de Iniciação Científica em Design de Moda. 2016. Anais do 12o Colóquio de Moda - 9o Edição Internacional. 3o Congresso Brasileiro de Iniciação Científica em Design de Moda. 2016.

SIMIONI, Ana Paula Cavalcanti. Regina Gomide Graz: modernismo, arte têxtil e relações de gênero no Brasil. Revista do IEB, n 45, p. 87-106, set 2007.

STAHN, M.O; PAZMINO, A. V. Renda de Bilros: Origens e Influências Culturais. In: 10o Congresso Brasileiro de Pesquisa e Desenvolvimento em Design, São Luís, 2012. Anais do 10o Congresso Brasileiro de Pesquisa e Desenvolvimento em Design, de 10 a 13 de outubro 2012, São Luís. p. 8425. 